\title{
MEMÓRIA DE EVENTO
PRÁTICAS DE GESTÃO DO CONHECIMENTO EM
PROGRAMAS AMBIENTAIS DO RITO DO
LICENCIAMENTO AMBIENTAL DE COMPLEXOS EÓLICOS ${ }^{1}$
}

\author{
Marcus Phoebe Farias Hinnig \\ Mestrando em Engenharia e Gestão do Conhecimento pela Universidade \\ Federal de Santa Catarina, Brasil. \\ E-mail: marcusphoebe@gmail.com \\ Eduardo Juan Soriano Sierra \\ Doutor em Ecologia de Ecossistemas pela Universidade Bordeaux I, França. \\ Professor da Universidade Federal de Santa Catarina, Brasil. \\ Email: eduardo.soriano.sierra@ufsc.br \\ Patrícia de Sá Freire \\ Doutora em Engenharia e Gestão do Conhecimento pela Universidade \\ Federal de Santa Catarina, Brasil. Professora da Universidade Federal de \\ Santa Catarina, Brasil. \\ E-mail: patriciadesafreire@gmail.com
}

\begin{abstract}
Resumo
O licenciamento ambiental é necessário para a implantação de empreendimentos que possam gerar impactos ao meio ambiente. Dentre estes empreendimentos, destacam-se os de infraestrutura e obras de grande vulto, como o caso de complexos eólicos. Para que estas obras sejam implantadas é necessário que se cumpra com diversas condicionantes ambientais exigidas pelo órgão licenciador, onde uma das ações é a execução de programas ambientais. Para a execução dos programas ambientais, a equipe de meio ambiente necessita replicar conhecimentos adquiridos em obras anteriores ou ainda consultar a base de dados disponível no órgão ambiental, todavia é comum se desperdiçar conhecimento. A Gestão do Conhecimento tem como objetivo administrar o conhecimento de forma eficiente, possibilitando às organizações trabalhar mais e melhor. $O$ objetivo deste trabalho é identificar práticas de gestão do conhecimento utilizadas por coordenadores de programas ambientais durante $o$ rito do licenciamento ambiental de complexos eólicos. Esta pesquisa aplicada possui abordagem predominantemente qualitativa com finalidade descritiva. O procedimento de pesquisa utilizado é o estudo de caso, fazendo-se o uso de questionários como instrumentos de coleta de dados junto à executores de programas ambientais de dois projetos de construção de complexos eólicos. Como resultado da pesquisa, além da identificação de barreiras e facilitadores para gestão do conhecimento no licenciamento ambiental, verifica-se a necessidade de melhorar a disponibilização de dados, informações e conhecimentos relativos aos resultados de estudos e programas ambientais já realizados.
\end{abstract}

Palavras-chave: Políticas públicas. Gestão do Conhecimento. Energia Eólica. Licenciamento Ambiental. Brasil.

\footnotetext{
${ }^{1}$ Fast Track resultante do VII Simpósio Internacional de Gestão de Projetos, Inovação e Sustentabilidade (SINGEP), realizado em São Paulo, entre 22 e 23 de outubro de 2018.
} 


\title{
PRACTICES OF KNOWLEDGE MANAGEMENT IN ENVIRONMENTAL PROGRAMS RELATED TO WIND POWER PLANT ENVIRONMENTAL LICENSING
}

\begin{abstract}
The environmental licensing process is requisite for the implementation of projects that may impact the environment. Among these projects, we highlight the infrastructure such as the case of wind power plants. In order to these projects to be implemented it is necessary to comply with several environmental constraints required by the licensing body, where one of the actions is the execution of environmental programs. To carry out the environmental programs, the environmental team needs to replicate knowledge acquired in previous works or consult the database available in the environmental body, however it is common that a lot of the knowledge be wasted. Knowledge Management aims to manage knowledge efficiently, enabling organizations to work more and better. The objective of this work is to identify knowledge management practices used by coordinators of environmental programs during the environmental licensing processes of wind farms. The research procedure used is the case study, making use of questionnaires as instruments of data collection with the environmental programs executors of two wind power plants construction projects. As a result of the research, besides the identification of the obstacles and facilitators for knowledge management in environmental licensing, it was identifyed the need to improve the availability of data, information and knowledge related to the results of environmental studies and programs already carried out.
\end{abstract}

Keywords: Public Policies. Knowledge Management. Wind Energy. Environmental permit. Brazil.

\section{INTRODUÇÃO}

O crescimento das cidades pode ser planejado para mitigar os impactos sobre o meio ambiente natural, a sociedade e a economia promovendo cidades sustentáveis (TRINDADE et al, 2017). Para garantir que os novos empreendimentos tenham controle sobre seus impactos ambientais o Brasil conta com um processo de licenciamento ambiental (CONAMA, 1997) que promove uma discussão sobre as alternativas tecnológicas, locacionais e de controle para a implantação e operação dos empreendimentos.

No caso de empreendimentos de energia, como usinas hidrelétricas, solares e eólicas, muitas vezes as obras são realizadas em áreas remotas e envoltas em ambiente natural, somada a presença de comunidades tradicionais e áreas de preservação. Com isso o desafio de se conciliar a existência do empreendimento com a preservação da natureza passa a ser uma grande responsabilidade do empreendedor.

Durante muitos anos o Brasil teve a hegemonia da presença de hidrelétricas e termelétricas em sua matriz energética, com tímida presença de usinas eólicas e solares. Contudo, quando comparada com a energia termelétrica e hidrelétrica, a energia eólica tem ganhado espaço nos últimos anos. Em outros países a produção de energia alternativa passou a ganhar força a partir de 1970 com a crise do petróleo (SIMAS, 2012). Já no Brasil as fragilidades observadas devido aos episódios de crise hídrica impulsionaram o governo a diversificar a sua matriz energética, investindo em energia eólica, solar e biomassa.

No Brasil, hoje a energia eólica representa cerca de $7 \%$ da matriz energética total, aumentando de 245 MW em 2005 para aproximadamente 13.000 MW em 2017 (ABEEOLICA, 2016). Embora não seja a principal fonte de energia nacional, o Brasil atualmente ocupa a 9o colocação em produção de energia eólica, estando a frente de países como Canadá e Itália (WWEA, 2018). Isso faz com que as geradoras de energia precisem aprender mais sobre as novas tecnologias, métodos de implantação e também sobre o licenciamento ambiental no Brasil.

Perspectivas em Gestão \& Conhecimento, João Pessoa, v. 9, n. 1, p. 266-284, jan./abr. 2019. 
Para que a licença ambiental de operação do empreendimento de energia eólica seja fornecida, o empreendedor deve primeiramente requerer as licenças prévia e de instalação para o órgão ambiental, onde são apresentados os projetos e levantados os impactos ambientais de sua implantação (CONAMA, 1997). Durante a implantação do empreendimento, deve-se executar programas ambientais, como monitoramento de recursos hídricos, de ruídos, arqueológico, resgate de fauna e flora dentre outras atividades de cunho social como comunicação social e parceria com órgãos públicos.

Com isso, faz-se necessária a presença de uma equipe multidisciplinar para que seja possível atender todas as condicionantes ambientais solicitadas pelo órgão ambiental. Muitas vezes a alocação de profissionais de disciplinas tão distintas só é possível com a contratação de empresas de consultoria.

Para se otimizar o licenciamento, do ponto de vista do empreendedor se faz necessário otimizar o conhecimento existente de toda a equipe pois as questões ambientais relacionadas a um empreendimento deste tipo compreendem a articulação de saberes formais, explícitos e implícitos (VIEGAS, 2009).

Diversas práticas de gestão do conhecimento podem ser utilizadas para que os saberes da equipe sejam incorporados ao conhecimento organizacional, como o caso da prática de Lições Aprendidas, utilizada para transmitir o conhecimento experiencial que é aplicado a uma tarefa, decisão ou processo, trazendo resultados positivos para a organização (WEBER, AHA, 2003).

Este artigo se propõe a identificar as práticas de aquisição e utilização do conhecimento por coordenadores de programas ambientais para o atendimento do rito do licenciamento ambiental no Brasil.

\section{REFERENCIAL TEÓRICO}

Nesta seção serão apresentados os referenciais teóricos de Gestão do Conhecimento, Licenciamento Ambiental e Energia Eólica.

\subsection{Gestão do Conhecimento}

De forma implícita, a gestão do conhecimento sempre existiu na sociedade, onde as boas práticas e experiência eram passadas de gerações em gerações, todavia enquanto disciplina e de forma explícita, veio ocorrer na década de 1980 (WIIG, 1997).

A Gestão do Conhecimento tem como função planejar, implantar, operar e monitorar as atividades necessárias para o gerenciamento eficaz do capital intelectual, incluindo criar, adquirir, transformar e utilizar este conhecimento (WIIG, 1997).

A Gestão do Conhecimento é procurada pelas empresas para melhorar a eficácia organizacional e, consequentemente, a sua competitividade, abrangendo criar, avaliar e disseminar os conhecimentos organizacionais (WIIG, 1997).

Para se entender melhor o objetivo da Gestão do Conhecimento é necessário levar em consideração o objeto que está se propondo gerir, a saber: o conhecimento. Neste sentido, se considerarmos o gerenciamento de qualquer outro recurso, deve-se ter como metas entregar o recurso no momento e lugar correto, além de satisfazer os quesitos de qualidade com os menores custos possíveis (WIIG et al., 1997).

Agora, tratando-se do objeto conhecimento, este possui características que o diferenciam dos demais recursos (WIIG et al., 1997) como por exemplo ser intangível, volátil e não diminui devido ao seu uso nem há problema em utilizá-lo em diferentes processos concomitantemente (WIIG et al, 1997).

Perspectivas em Gestão \& Conhecimento, João Pessoa, v. 9, n. 1, p. 266-284, jan./abr. 2019. 
Para que determinada organização se mantenha competitiva, deve ter a capacidade de criar conhecimento (NONAKA; TAKEUCHI, 1997) e, por este motivo, deve ser identificado, explicitado e socializado para ser incorporado ao conhecimento organizacional, evitando assim o desperdício de conhecimento (FERENHOF, 2011).

O conhecimento pode ser dividido em tácito e explícito, sendo o primeiro mais relacionado com experiências pessoais, subjetivo e difícil de ser representado, enquanto o conhecimento explícito é objetivo, capaz de ser transmitido através de fórmulas e textos (NONAKA et al, 2003). Estes conhecimentos são essenciais para a organização e juntos devem ser utilizados para o desenvolvimento de novos conhecimentos. Estas características que diferem os conhecimentos tácito e explícito são apresentadas no Quadro 1:

Quadro 1 - Comparação entre propriedades dos conhecimentos tácito e explícito

\begin{tabular}{|c|c|}
\hline Propriedades do conhecimento tácito & Propriedades do conhecimento explícito \\
\hline $\begin{array}{l}\text { Capacidade de se adaptar em novas e excepcionais } \\
\text { situações }\end{array}$ & $\begin{array}{c}\text { Capacidade de disseminar, reproduzir, acessar e } \\
\text { reaplicar através da organização }\end{array}$ \\
\hline Expertise, know-how, know-why & Capacidade para ensinar e treinar \\
\hline $\begin{array}{c}\text { Capacidade de colaborar, compartilhar a visão e } \\
\text { transmitir cultura }\end{array}$ & $\begin{array}{c}\text { Capacidade de organizar, sistematizar, transmitir } \\
\text { uma visão através da declaração da missão e guias } \\
\text { operacionais }\end{array}$ \\
\hline $\begin{array}{l}\text { Coaching e Mentoring para transferir } \\
\text { conhecimento experiencial }\end{array}$ & $\begin{array}{c}\text { Transferência de conhecimento via produtos, } \\
\text { serviços e processos }\end{array}$ \\
\hline
\end{tabular}

Fonte: Dalkir (2005)

A Gestão do Conhecimento, enquanto disciplina, tem potencializado a utilização de conhecimento para gerar vantagens competitivas das organizações (DOS SANTOS PACHECO, 2008). Noutras palavras, o objetivo da Gestão do Conhecimento nada mais é do que proporcionar a administração do conhecimento de forma eficiente, possibilitando às organizações trabalhar mais e melhor (WIIG, 1997).

Cabe ainda salientar que existem duas formas de abordagem da gestão do conhecimento, a primeira é relacionada à melhoria no fluxo de conhecimento entre indivíduos e a organização e outra voltada para às contribuições da Tecnologia da Informação nos processos organizacionais (GONZALES, MARTINS, 2017).

O processo de Gestão do Conhecimento pode ser dividido em diferentes etapas, sendo que determinados autores apresentam proposições diferentes para a sua classificação e denominação. Neste trabalho, porém, será utilizada a divisão proposta por Gonzales e Martins (2017), por ser mais sucinta e comportar a mesclagem e compatibilização das etapas propostas por outros autores, conforme apresentado na Figura 1:

Figura 1 - Processo de Gestão do Conhecimento
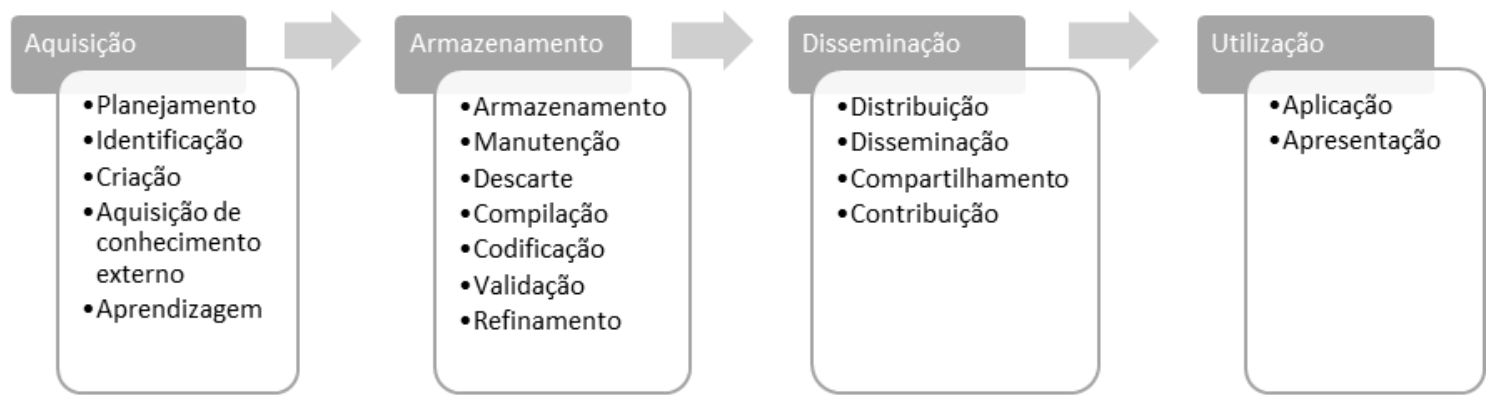

Fonte: O autor (2018)

Perspectivas em Gestão \& Conhecimento, João Pessoa, v. 9, n. 1, p. 266-284, jan./abr. 2019. 
Conforme apresentado na Figura 1, neste artigo a etapa de Aquisição considera outras atividades como a identificação e criação do conhecimento, a etapa de armazenamento contempla a codificação e validação do conhecimento, a etapa de disseminação abrange também o compartilhamento e a etapa de utilização engloba a aplicação do conhecimento. $O$ Quadro 2 detalha as etapas do processo de Gestão do Conhecimento e seus objetivos em quatro etapas básicas: aquisição, armazenamento, disseminação/ distribuição e utilização do conhecimento (GONZALES; MARTINS, 2017).

Quadro 2 - Objetivos das fases de gestão do conhecimento

\begin{tabular}{|c|c|}
\hline Fase & Objetivos centrais \\
\hline Aquisição & 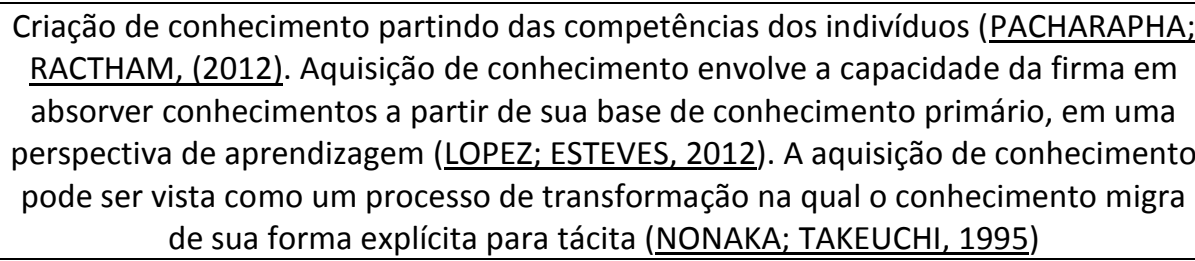 \\
\hline Armazenamento & $\begin{array}{l}\text { Retenção do conhecimento gerado pelos indivíduos e socializado nos grupos } \\
\text { (YIGITCANLAR et al., 2007), formando uma memória organizacional (WALSH; } \\
\text { UNGSON, 1991). Processo de explicitação do conhecimento tácito (NONAKA; } \\
\text { TAKEUCHI, 1995). Desenvolvimento de uma cultura e estrutura organizacional que } \\
\text { represente a rotina da empresa (MADSEN et al., 2003). }\end{array}$ \\
\hline Distribuição & $\begin{array}{l}\text { Disseminação do conhecimento entre os indivíduos por meio do contínuo contato } \\
\text { social (LEVINE; PRIETULA, 2012); e de grupos especializados que compartilhem uma } \\
\text { linguagem e objetivos, numa abordagem de comunidade de prática (BROWN; } \\
\text { DUGUID, 2001). Utilização de TI como facilitador do processo de disseminação. }\end{array}$ \\
\hline Utilização & $\begin{array}{l}\text { O conhecimento da firma sendo explotado (forma reativa) ou explorado (forma } \\
\text { inovativa) (COHEN; LEVINTHAL, 1990). A utilização do conhecimento a fim de } \\
\text { reconstruir suas rotinas e competências (VOLBERDA et al., 2010). Recuperação e } \\
\text { transformação do conhecimento adquirido promovendo a ampliação da base de } \\
\text { conhecimento organizacional (WALSH; UNGSON, 1991) }\end{array}$ \\
\hline
\end{tabular}
Fonte: Gonzales e Martins (2017)

Desta forma, o Quadro 2 apresenta as quatro etapas do processo de gestão do conhecimento propostas por Gonzales e Martins (2017): A etapa de aquisição do conhecimento está relacionada com a criação do conhecimento na organização ou na aquisição de conhecimento externo; $\mathrm{O}$ armazenamento se refere à memória organizacional que pode estar dividida entre indivíduo, na forma de retenção de conhecimento tácito, na organização, como institucionalização do conhecimento, ou ainda na Tecnologia da Informação (TI), a partir do armazenamento de conhecimento explícito; A disseminação diz respeito à possibilidades de contato direto, ou via $\mathrm{TI}$, entre os indivíduos da organização visando disseminar a parcela tácita e implícita do conhecimento; e a utilização do conhecimento, focada em localizar, acessar e utilizar todo o conhecimento criado e armazenado.

Para que a organização possa abordar as diferentes etapas do processo de gestão do conhecimento, faz-se necessário o uso de diferentes ferramentas, tecnologias e artifícios, os quais também devem atender a expectativa das diferentes pessoas e gerações (DALKIR, 2005). Isto posto, para uma gestão do conhecimento eficaz, é necessário compreender suas fases, bem como sobre os métodos, técnicas e ferramentas que proporcionam a sua realização. 
Vistos os conceitos e processos relativos à gestão do conhecimento, nos próximos capítulos serão tratados os temas licenciamento ambiental, energia eólica e impactos ambientais relativos à empreendimentos eólicos.

\subsection{Licenciamento ambiental}

A Avaliação de Impactos Ambientais (AIA) tem como função verificar a viabilidade da implantação de um empreendimento considerando critérios como manutenção de fauna, flora, recursos hídricos, patrimônio arqueológico além dos danos à população e vizinhança (BARBIERI, 1995).

Foi nos Estados Unidos da América - EUA que se iniciou a exigência da realização da avaliação de impactos ambientais para empreendimentos de potencial impacto ambiental, o que se deu a partir da promulgação da Lei The National Environmental Policy Act (NEPA) em 1969 (ANDERSON, 2013).

Em seguida diversos países passaram a cobrar a avaliação de impacto ambiental mesmo sem ter legislação específica para este estudo, como no caso de Portugal que teve sua lei publicada somente em 1987 (BARBIERI, 1995).

A avaliação de impactos ambientais também foi impulsionada por instituições como o Banco Mundial que passaram, a partir da realização da I Conferência das Nações Unidas sobre Desenvolvimento Humano e Meio Ambiente realizada em Estocolmo em 1972, a exigir sua elaboração enquanto contrapartida do fomento de obras de grande vulto em países subdesenvolvidos (VIEGAS, 2009).

Em pouco tempo diversos países estavam considerando a realização da avaliação de impactos ambientais na construção de suas grandes obras, a exemplo de Canadá, Nova Zelândia e Austrália na década de 1970 e, União Europeia, União das Repúblicas Socialistas Soviéticas, Espanha e Holanda na década de 1980 (VIEGAS, 2009).

No Brasil o primeiro empreendimento considerado a aplicar a avaliação de impacto ambiental foi a Hidrelétrica de Sobradinho, em 1972, para que o empréstimo do Banco Mundial fosse concedido (BARBIERI, 1995). A legislação ambiental brasileira que passou a considerar a avaliação de impactos ambientais, por sua vez, só veio em 1981 com a Política Nacional de Meio Ambiente (Lei 6.938/81).

A Política Nacional de Meio Ambiental apresenta, dentre seus instrumentos a avaliação de impactos ambientais e o licenciamento ambiental, onde os empreendedores necessitam cumprir etapas e pré-requisitos até que se possa construir os empreendimentos e em seguida operá-los. Um dos estudos necessários para empreendimentos de grande vulto é o Estudo de Impacto Ambiental - EIA, que contém a caracterização do empreendimento, a identificação e avaliação dos seus possíveis impactos ambientais e, por último, a proposição de medidas mitigadoras, compensatórias, de controle para os impactos negativos ou potencializadoras para os impactos positivos (MMA, 2009).

Enquanto a avaliação de impactos está focada na análise técnica e analítica de impactos e na proposição de alternativas para viabilizar o projeto, o licenciamento ambiental pode ser entendido como o rito administrativo onde o órgão ambiental dá concessões, na forma de licenças ambientais, ao empreendedor a medida que este apresenta os estudos e documentos solicitados (CONAMA, 1997).

Quando um empreendedor submete um projeto ao órgão ambiental, deverá, em regra geral, apresentar documentos e estudos solicitados para só então receber a Licença Prévia, em seguida a Licença de Instalação e por último a Licença de Operação do empreendimento. Desta forma, pode-se afirmar que o licenciamento ambiental contribui para a promoção do controle ambiental de empreendimentos, seja na sua concepção, sua instalação ou seja na sua operação (MMA, 2009).

Perspectivas em Gestão \& Conhecimento, João Pessoa, v. 9, n. 1, p. 266-284, jan./abr. 2019. 
Os programas ambientais devem ser executados pelo empreendedor como forma de mitigar e compensar os impactos negativos identificados nos estudos ambientais preliminares ou ainda potencializar os impactos positivos. A relação dos programas ambientais com as fases de licença ambiental está apresentada na Figura 2:

Figura 2 - Relação dos programas ambientais com as fases de licenciamento ambiental no Brasil
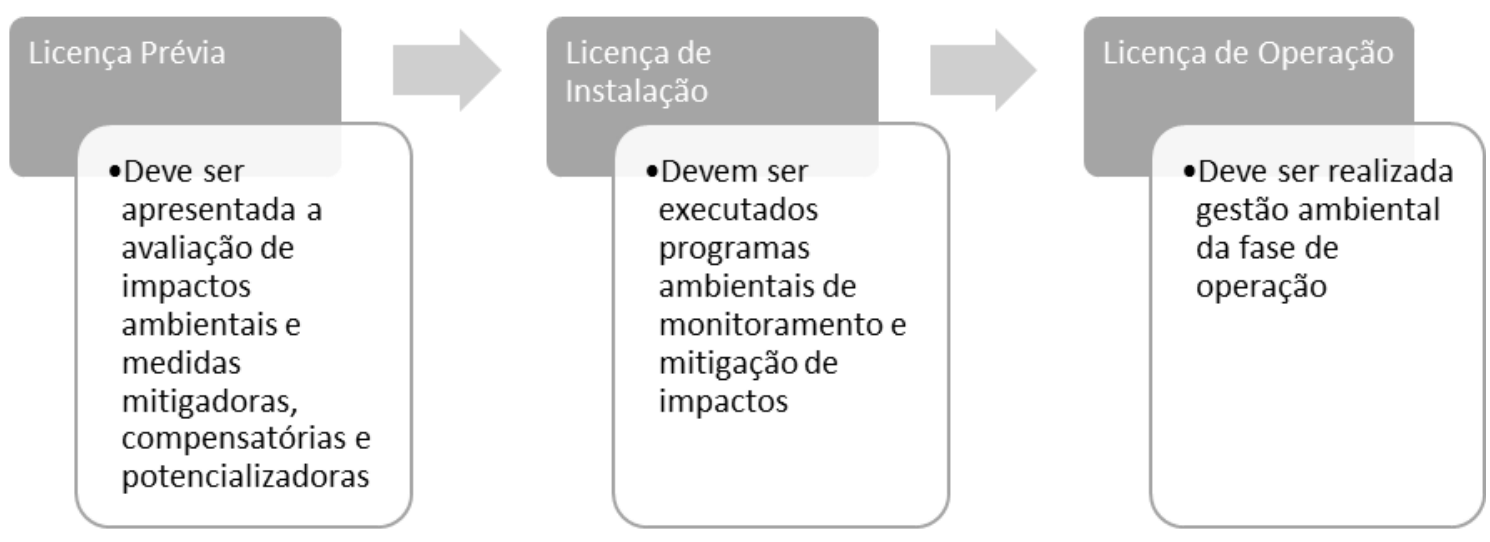

Fonte: Elaborado pelos autores (2018) a partir de CONAMA (1997)

Dentre os empreendimentos sujeitos ao licenciamento ambiental pode-se citar atividades como extração e tratamento de minerais, indústria química, indústria de produtos alimentares e bebidas, obras civis, atividades agropecuárias, uso de recursos naturais e empreendimentos de geração e transmissão de energia.

Neste artigo será abordado o tipo de empreendimento denominado usina de geração de energia eólica o qual é pormenorizado no próximo capítulo.

\subsection{Energia Eólica}

As discussões sobre a utilização de energias renováveis como a solar, eólica e geotérmica são antigas, todavia a sua implantação muitas vezes esbarra na oferta de opções mais baratas como os combustíveis fósseis ou o uso de urânio, somado às estratégias governamentais como a regulamentação de preços de determinados combustíveis como o gás natural (WEINBERG, 1979).

Mesmo assim, em cenário de crise energética, ameaças sobre a disponibilidade de combustíveis convencionais e de conscientização ambiental mais latente, as energias renováveis têm ganhado espaço na matriz energética de vários países. A energia renovável é considerada como fonte de energia limpa, sendo que a otimização dos recursos naturais minimiza os impactos ambientais, produzem menos resíduos e são mais compatíveis com as necessidades socioeconômicas atuais e futuras (PANWAR et al, 2011). Em especial, os países em desenvolvimento, dos quais fazem parte Brasil, China e Índia, tiveram um crescimento de 36\% nos investimentos em energias renováveis a partir de 2013 (CEDRICK; LONG, 2017). 
As energias renováveis trazem diversos benefícios socioeconômicos, tais quais a inovação tecnológica, o desenvolvimento industrial, a geração distribuída, a universalização do acesso à energia e a eficiência na utilização de recursos naturais (SIMAS, 2012).

Como fatores limitantes, pode-se esbarrar em problemas fundiários devido à formação de lagos ou a alteração na beleza cênica no caso das hidrelétricas, e a necessidade do uso de materiais especiais, tais quais como o cromo e o níquel para a construção de energia solar e eólica (MCCOMBIE, JEFFERSON, 2016). Um dos maiores desafios, porém, trata-se da necessidade de investimentos iniciais elevados para a sua construção, justamente por demandar tecnologia de ponta e inovação, todavia está sendo sanado com a participação de parcerias público privadas ao redor do mundo (CEDRICK; LONG, 2017).

Contudo, quando comparada com a energia nuclear, termelétrica e hidrelétrica, a energia eólica tem ganhado espaço ano após ano. Mundialmente, as energias alternativas passaram a ganhar força a partir de 1970 com a crise do petróleo (SIMAS, 2012). No caso do Brasil, alguns episódios de crise hídrica, por exemplo, impulsionaram o governo a diversificar a sua matriz energética, investindo em energia eólica, solar e biomassa.

No Brasil, a energia eólica tem se destacado por seu crescimento, representando hoje cerca de $7 \%$ da matriz energética total, aumentando de 245 MW em 2005 para aproximadamente $13.000 \mathrm{MW}$ em 2017, conforme esperado pelo incremento do resultado dos leilões já contratados pelo governo (ABEEOLICA, 2016).

É importante destacar também que o Brasil tem elevado potencial de geração de energia eólica, mas também de investimentos no setor, o que fazem do país o nono em capacidade instalada de geração de energia eólica e em quinto se considerado somente o incremento no ano de 2016 (ANEEL, 2017).

Um aerogerador é o equipamento responsável por transformar a energia cinética em energia elétrica, sendo formado por uma torre, as pás, a nacele, o cubo e diversos subcomponentes (FERREIRA, 2017). De acordo com a Resolução CONAMA № 462/2014 um conjunto de aerogeradores é chamado de parque eólico, enquanto a soma de parques eólicos pode ser chamada de complexo eólico. Esta concentração de aerogeradores é responsável pela geração representativa de energia.

O capítulo que segue tem o objetivo de indicar quais os principais impactos concernentes à implantação de empreendimentos eólicos.

\subsection{Impactos Ambientais em Empreendimentos Eólicos}

A implantação e operação de empreendimentos eólicos pode acarretar na geração de impactos ambientais positivos e negativos, sejam para o meio físico, biótico ou socioeconômico (STAUT, 2011).

Os principais potenciais impactos de uma usina eólica de acordo com o Ministério de Meio Ambiente (MMA, 2018), incidem sobre a fauna, paisagismo, uso do solo, erosão, drenagem, ruídos, interferência eletromagnética e impactos socioeconômicos (positivos e negativos). Já os principais benefícios proporcionados pelas usinas eólicas, de acordo com a Associação Brasileira de Energia Eólica (ABEEOLICA, 2017) são:

- Uso de energia renovável

- Não emissão de $\mathrm{CO}_{2}$

- Custo benefício da tarifa de energia competitivo

- Possibilidade de o proprietário da terra permanecer com plantações e criação de animais

- Geração de renda e qualidade de vida a partir do arrendamento das terras

- Fixação do homem no campo 
- Custo menor do que outras fontes de energia.

- Capacitação da mão-de-obra local

Como benefícios da energia eólica, pode-se citar ainda o seu caráter renovável e amigável quando comparada às demais usinas de geração de energia. Quando levamos em consideração a cadeia produtiva da construção de aerogeradores, é evidente a geração de diversos empregos sobretudo pela necessidade de constante inovação em todos os seus subcomponentes (SIMAS, 2012). O seu caráter inovativo pode ser constatado pelo elevado número de patentes por empresas e universidades como também pelo incremento de potência dos aerogeradores (FERREIRA, 2017).

Após aprovado o projeto e programas ambientais junto ao órgão ambiental, é então concedida uma licença de instalação ao empreendedor, licença esta que impõe a execução para programas ambientais que irão mitigar, compensar ou potencializar os impactos supramencionados (CONAMA, 1997).

Desta forma, para os impactos sobre aves e morcegos, por exemplo, é solicitado ao empreendedor que se realize o monitoramento de avifauna e de quirópteros, respectivamente. Devido à especificidade de cada programa ambiental, o empreendedor pode necessitar de várias empresas ou profissionais executores.

Cada responsável pela execução de um programa ambiental, então, utiliza seus conhecimentos adquiridos em projetos anteriores somados aos conhecimentos do órgão ambiental e do empreendedor para a realização do novo trabalho. As equipes de programas ambientais, lideradas por coordenadores, são responsáveis por evidenciar, a partir de registros fotográficos e relatórios, o cumprimento das condicionantes ambientais impostas pelo órgão ambiental.

Este estudo apresenta, portanto, as práticas apontadas por estes coordenadores de programas ambientais para aplicar nos seus projetos, o conhecimento já existente sobre a execução dos programas ambientais que lhe foram confiados. O próximo capítulo apresentará a metodologia utilizada neste estudo de caso.

\section{METODOLOGIA}

A abordagem adotada para a presente pesquisa foi a pesquisa qualitativa que pode ser entendida como um conjunto de técnicas que buscam compreender os elementos e fenômenos do mundo social (NEVES, 1996). A pesquisa qualitativa é um processo rico no que se refere à descrição, de uma maneira geral, e que tem como foco o próprio processo, além da compreensão e significado das respostas da pesquisa (MERRIAM, 2015). Para a sua realização é comum a utilização de entrevistas, viabilizando assim a compreensão do evento a ser estudado (DUARTE, 2002).

O método de pesquisa aplicado foi o Estudo de Caso que, de acordo com Merriam (2015) é voltado para avaliar questões subjetivas de um sistema limitado. O estudo de caso deve ser específico, bem delimitado e contextualizado, possibilitando a busca circunstanciada de informações (VENTURA, 2007). O estudo de caso enquanto delineamento de pesquisa possibilita ainda incorporar conhecimentos tácitos e explícitos (GIL, 2002), enriquecendo os resultados. As fases executadas neste estudo de caso atenderam a proposta de Yin (2001), que compreendem a formulação do problema; definição da unidade-caso; determinação do número de casos; elaboração do protocolo; coleta de dados; avaliação e análise dos dados; e preparação do relatório. Nesta pesquisa foi realizado um estudo de caso múltiplo, com equipes de coordenadores de meio ambiente de dois complexos eólicos similares e contíguos, denominados CE-A e CE-B. A coleta de dados se deu pela análise de documentos e questionários. A organização escolhida para a pesquisa é uma grande geradora de energia que

Perspectivas em Gestão \& Conhecimento, João Pessoa, v. 9, n. 1, p. 266-284, jan./abr. 2019. 
atua no Brasil construindo e operando usinas hidrelétricas, eólicas e termelétricas, sendo esta a proprietária dos projetos $\mathrm{CE}-\mathrm{A}$ e CE-B, abordados nesta pesquisa.

As obras do Projeto CE-A foram iniciadas no ano de 2016 e tem previsão de conclusão em 2018, enquanto o Projeto CE-B iniciou em 2017 e tem finalização estimada no ano de 2019. Desta forma, o empreendedor já possuía conhecimentos inerentes à realidade local quando iniciou o Projeto CE-B. As equipes contratadas para a execução dos programas ambientais, porém, foram diferentes para os projetos CE-A e CE-B.

Os questionários foram aplicados com a totalidade das empresas de consultoria que possuíam coordenadores de programas ambientais dos dois projetos, evitando profissionais que atuam em atividades esporádicas ou pontuais. No total, foram aplicados dez questionários. Foram seguidos os seguintes requisitos para aplicação dos questionários junto aos coordenadores de programas ambientais: Ser responsáveis pelas atividades de meio ambiente diárias na obra (gerenciamento de resíduos, recuperação de áreas degradadas, etc.), ou; realizam campanhas de monitoramento com periodicidade inferior a 6 meses. O Quadro 3 sumariza o perfil dos dez coordenadores que participaram da pesquisa.

Quadro 3 - Perfil dos entrevistados

\begin{tabular}{|c|c|c|}
\hline ID & Formação & Anos de experiência \\
\hline 1 & Eng. Ambiental e Especialização em Eng. de Segurança do Trabalho & 10 \\
\hline 2 & Arqueólogo & 10 \\
\hline 3 & Engenheiro Florestal MSc. & 5 \\
\hline 4 & Engenheiro Agrícola e Ambiental & 7 \\
\hline 5 & Eng Sanitarista e Ambiental & 2 \\
\hline 6 & Engenheiro Sanitarista, Ambiental e de Segurança do Trabalho & 14 \\
\hline 7 & Eng. Ambiental e de Segurança do Trabalho & 4 \\
\hline 8 & Técnico Ambiental & 8 \\
\hline 9 & Engenheiro Sanitarista & 32 \\
\hline 10 & Tecnólogo em Gestão Ambiental & 6 \\
\hline
\end{tabular}

Fonte: Dados da pesquisa (2018)

O questionário foi aplicado por meio de formulário eletrônico devido à dificuldade do contato presencial e simultâneo com os coordenadores, uma vez que suas empresas estão localizadas em diferentes Estados do Brasil e pelo fato de não estarem presencialmente na obra em período integral.

Ante aos poucos trabalhos publicados relacionando o processo de gestão do conhecimento com a execução de programas ambientais na fase de implantação de complexos eólicos, a aplicação do instrumento de pesquisa foi validada por profissional com elevada experiência no licenciamento dos empreendimentos da organização proprietária dos CL-A e $\mathrm{CL}-\mathrm{B}$. As sentenças aplicadas no questionário foram:

Quadro 4 - Sentenças aplicadas nos questionários

\begin{tabular}{|c|c|}
\hline$\#$ & Sentença \\
\hline 1 & $\begin{array}{r}\text { Com relação ao rito do licenciamento ambiental, quais as principais barreiras para adquirir } \\
\text { conhecimentos inerentes à execução de programas ambientais? }\end{array}$ \\
\hline 2 & $\begin{array}{r}\text { Com relação ao rito do licenciamento ambiental, quais os principais facilitadores para adquirir } \\
\text { conhecimentos inerentes à execução de programas ambientais? }\end{array}$ \\
\hline 3 & $\begin{array}{r}\text { Como você transmite o conhecimento de meio ambiente adquirido nos teus projetos já } \\
\text { realizados para os teus projetos atuais e futuros? }\end{array}$ \\
\hline 4 & $\begin{array}{r}\text { Como você coleta e utiliza as informações disponíveis no órgão ambiental sobre } \\
\text { empreendimentos similares ou área de estudo nos projetos ambientais que você coordena? }\end{array}$ \\
\hline
\end{tabular}

Perspectivas em Gestão \& Conhecimento, João Pessoa, v. 9, n. 1, p. 266-284, jan./abr. 2019. 
Fonte: Elaborado pelos autores (2018)

Conforme já mencionado, as pesquisas foram aplicadas com coordenadores de programas ambientais inerentes ao licenciamento ambiental de dois projetos similares em execução pela organização.

Os projetos compreendem a execução de complexos eólicos em região da caatinga brasileira onde se faz necessária a participação de uma equipe multidisciplinar formada por profissionais da Engenheira, Biólogia, Arquitetura, Arqueologia, Administração, Comunicação Social, entre outras formações. As entrevistas foram tabuladas em planilha eletrônica e seus resultados estão apresentados no próximo capítulo.

\section{APRESENTAÇÃO E ANÁLISE DOS RESULTADOS}

Este capítulo apresenta os resultados da aplicação dos questionários cujas sentenças encontram-se descritas no Quadro 4. A análise é feita primeiro para as questões 1 e 2 que tratam da identificação de barreiras e facilitadores para adquirir conhecimentos inerentes à execução de programas ambientais. Posteriormente é discutido o resultado das questões 3 e 4, voltadas para identificação de práticas de gestão do conhecimento para a aquisição e utilização do conhecimento.

As respostas dos questionários referentes às questões 1 e 2 , sobre barreiras e facilitadores para adquirir conhecimentos inerentes à execução de programas ambientais, estão tabuladas e divididas em categorias conforme apresentadas no Quadro 5:

Quadro 5 - Levantamento de barreiras e facilitadores para a gestão do conhecimento pelos coordenadores de meio ambiente entrevistados

\begin{tabular}{|c|c|}
\hline Barreiras & Facilitadores \\
\hline $\begin{array}{l}\text { Problemas relacionados aos profissionais sua rede de } \\
\text { contato } \\
\text { Falta de intercâmbio. } \\
\text { Falta de troca de experiências. } \\
\text { Falta de eventos. } \\
\text { Falta de estudos de casos. } \\
\text { Falta de ferramentas de gestão de tarefas e de } \\
\text { resultados. } \\
\text { Falta de experiência de coordenadores ambientais. } \\
\text { Problemas na disponibilização de informações } \\
\text { Falta de integração e ampla divulgação dos } \\
\text { resultados. } \\
\text { Inexistência de um banco de dados de fácil acesso. } \\
\text { Falta de mecanismos de dispersão dos } \\
\text { conhecimentos. } \\
\text { Legislação ambiental de difícil acesso. } \\
\text { Falta de padronização no entendimento dos } \\
\text { diferentes órgãos ambientais competentes. } \\
\text { Falta de material científico específico e aprofundado. } \\
\text { Problemas nas atividades de ensino } \\
\text { Falta de abordagens práticas na academia. } \\
\text { Falta de conhecimento prático dos professores. }\end{array}$ & $\begin{array}{l}\text { Acesso à informação } \\
\text { Serviços de transparência pública. } \\
\text { Fase de consulta pública. } \\
\text { Legislação ambiental. } \\
\text { Informatização dos sistemas de informações } \\
\text { dos órgãos ambientais. } \\
\text { Internet. } \\
\text { Sites de institutos de pesquisa. } \\
\text { Artigos científicos. } \\
\text { Bancos de dados de informações anteriores } \\
\text { sobre processos e estudos já executados. } \\
\text { A acessibilidade dos materiais produzidos } \\
\text { disponíveis nos meios digitais. } \\
\text { Sistematização das informações. } \\
\text { Ferramenta de geolocalização. } \\
\text { A gestão das informações obtidas. } \\
\text { Experiência e habilidades dos consultores } \\
\text { Experiência pretérita com outros programas } \\
\text { ambientais. } \\
\text { Competência dos profissionais. } \\
\text { Habilidades técnicas adquiridas com as } \\
\text { experiências. } \\
\text { Capacidade de gestão, organização }\end{array}$ \\
\hline
\end{tabular}

Perspectivas em Gestão \& Conhecimento, João Pessoa, v. 9, n. 1, p. 266-284, jan./abr. 2019. 


\begin{tabular}{|c|c|}
\hline Barreiras & Facilitadores \\
\hline $\begin{array}{l}\text { Maior atenção dada pela academia nos estudos dos } \\
\text { impactos em detrimento aos programas ambientais. } \\
\text { Estudos, planos e projetos ambientais deficientes } \\
\text { Baixa qualidade dos Programas Ambientais que } \\
\text { serviram para licenciamento do empreendimento. } \\
\text { Condicionantes ambientais genéricas. } \\
\text { O PBA traz ações incoerentes/ restritivas com a } \\
\text { implantação de empreendimentos. } \\
\text { PBA visando apenas a obtenção da licença ambiental. } \\
\text { Dificuldade de execução/ implantação de algumas } \\
\text { condicionantes ambientais devido ao PBA ser } \\
\text { restritivo ou de difícil aplicação. } \\
\text { Programas Ambientais que não condizem com a } \\
\text { realidade do local. } \\
\text { Órgão ambiental e legislação } \\
\text { Aspectos da legislação necessitam de discussão para } \\
\text { evoluir e serem mais efetivos } \\
\text { Interpretação difícil da legislação local; } \\
\text { Comunicação como órgão ambiental deficiente; } \\
\text { Procedimentos internos do órgão ambiental não } \\
\text { disponíveis à população }\end{array}$ & $\begin{array}{l}\text { comunicação do profissional. } \\
\text { Experiência prévia com o órgão ambiental } \\
\text { licenciador. } \\
\text { Consultores / colaboradores que possuem } \\
\text { experiência com o órgão ambiental na região } \\
\text { do empreendimento. } \\
\text { Atributos do Órgão Ambiental } \\
\text { Padronização das exigências e procedimentos. } \\
\text { Profissionais do órgão ambiental qualificados } \\
\text { para exercer as funções que lhe foram } \\
\text { conferidas. } \\
\text { Condicionantes ambientais condizentes ao tipo } \\
\text { de empreendimento. } \\
\text { Hierarquia e fluxo de informações claras na } \\
\text { estrutura organizacional. } \\
\text { Órgão ambiental ou legislação de fácil acesso e } \\
\text { explicativa. } \\
\text { Desburocratização do órgão ambiental. } \\
\text { Comunicação entre órgão ambiental e com o } \\
\text { elaborador dos programas ambientais. }\end{array}$ \\
\hline
\end{tabular}
Fonte: Dados da Pesquisa (2018)

Dentre as principais barreiras identificadas pelos coordenadores de programas ambientais foram citados desde problemas de falta de prática no assunto de licenciamento ambiental por parte dos professores até a falta de disponibilização de banco de dados ou informações consolidadas pelos órgãos ambientais.

As categorias apontadas no item barreiras foram: problemas relacionados aos profissionais e sua rede de contatos, problemas na disponibilização de informações pelo órgão ambiental, problemas nas atividades de ensino, estudos ambientais deficientes, e outros.

Com relação aos problemas vinculados à categoria de rede de contatos dos coordenadores, foram citados itens como a falta de eventos e oportunidades para a troca de experiências. De fato, o que ocorre é que mesmo que em alguma obra seja realizada uma ação de sucesso, dificilmente outras empresas ficarão sabendo pela falta de disseminação destas informações e conhecimentos na forma de estudo de caso.

Sobre os problemas apontados na disponibilização dos dados, muitas vezes os consultores ambientais só conseguem acesso à informação solicitando formalmente os dados para o órgão ambiental. Os coordenadores indicaram que uma melhor disponibilização dos dados na forma de banco de dados padronizado, por exemplo, deixaria de ser uma barreira à execução de programas ambientais.

Perspectivas em Gestão \& Conhecimento, João Pessoa, v. 9, n. 1, p. 266-284, jan./abr. 2019. 
Relata-se também alguns problemas vinculados na fase acadêmica, origem dos conhecimentos que serão utilizados nas obras. Nem sempre os alunos procuram informações sobre questões práticas e nem sempre é possível que os professores repassem questões do dia-a-dia da obra, portanto a experiência profissional, seja por estágios e visitas técnicas são fundamentais para a aquisição do conhecimento.

Outro aspecto relevante diz respeito ao Plano Básico Ambiental - PBA (ou Projeto Básico Ambiental), que é elaborado também por empresas de consultoria ambiental, mas que muitas vezes apresenta ações não aplicáveis à área de estudo, conforme dados da pesquisa. Por outro lado, foi citado que os órgãos ambientais impõem condicionantes ambientais genéricas, que muitas vezes não são aplicáveis ao empreendimento.

Foram apontadas ainda questões como a falta de recursos e de interesse por parte do empreendedor. Estas indicações, porém, foram realizadas por integrantes de equipes de empreiteiras que também prestam serviços de meio ambiente, como o gerenciamento de resíduos sólidos e recuperação de áreas degradadas, posicionamento este que destoa das respostas do restante dos entrevistados. Vale relembrar aqui que a aquisição e utilização do conhecimento independe da vontade do empreendedor, uma vez que a base de consulta é formada por livros, artigos, estudos já protocolados junto à órgãos ambientais, além da experiência da própria equipe.

Como facilitadores, foram apontados fatores principalmente relacionados à disponibilização de estudos e informações na internet. As categorias relacionadas, foram: Acesso à informação, experiência e habilidades dos consultores e, por último, órgão ambiental eficiente.

De forma geral, quando o órgão ambiental tem um sistema de disponibilização de dados via internet facilita a execução de novos estudos e programas ambientais. Como exemplo, podemos citar a comparação de metodologias para a execução de atividades relacionadas à supressão de vegetação, monitoramento de fauna e flora. É possível também recorrer à artigos científicos, embora seja mais comum a prática de acesso à estudos já realizados.

Um dos casos citados foi o banco de dados de arqueologia disponível para o todo o Brasil, o que facilita o trabalho de empresas de consultoria uma vez que não dependem da solicitação formal de dados para o órgão responsável, o Instituto do Patrimônio Histórico e Artístico Nacional (IPHAN).

Também foram levantados quesitos inerentes às habilidades do profissional, como a capacidade de gestão, experiência com projetos similares e até mesmo o conhecimento a respeito do órgão ambiental, que facilita por exemplo a realização de reuniões com a equipe técnica da instituição.

$\mathrm{Na}$ categoria relacionada à atributos do órgão ambiental, foram citados como facilitadores os profissionais do órgão ambiental qualificados para exercer as funções que the foram conferidas, pois caso contrário atrasam o processo e passam informações imprecisas; hierarquia e fluxo de informações claras na estrutura organizacional, pois é preciso identificar a quem recorrer no caso de dúvidas e sugestões e; legislação de fácil acesso e bem explicativa, não dando lugar a interpretação dúbia.

Ressalta-se que tanto as barreiras quanto os facilitadores indicados pelos entrevistados dizem respeito à sua experiência enquanto profissionais, abrangendo suas vivências noutros projetos, organizações e na interface com órgãos ambientais de diversos Estados brasileiros.

As respostas dos questionários referentes às questões 3 e 4, sobre práticas de gestão do conhecimento para os processos de aquisição e utilização, foram tabuladas e divididas em categorias e são apresentadas no Quadro 6:

Perspectivas em Gestão \& Conhecimento, João Pessoa, v. 9, n. 1, p. 266-284, jan./abr. 2019. 
Quadro 6 - Levantamento de práticas de gestão do conhecimento pelos coordenadores de meio ambiente entrevistados

\begin{tabular}{|c|c|}
\hline $\begin{array}{l}\text { Aquisição do Conhecimento } \\
\text { (junto ao órgão ambiental) }\end{array}$ & $\begin{array}{l}\text { Utilização do Conhecimento } \\
\text { (projetos pretéritos do consultor) }\end{array}$ \\
\hline 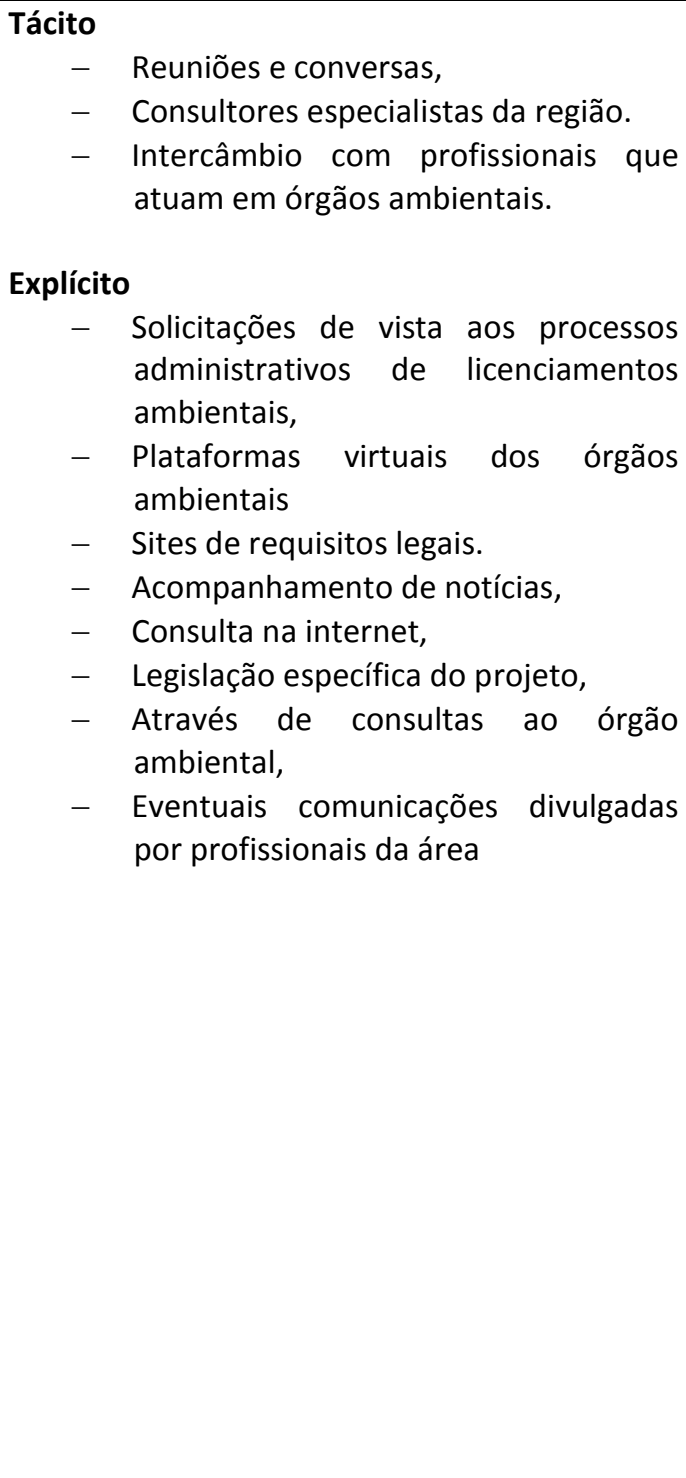 & 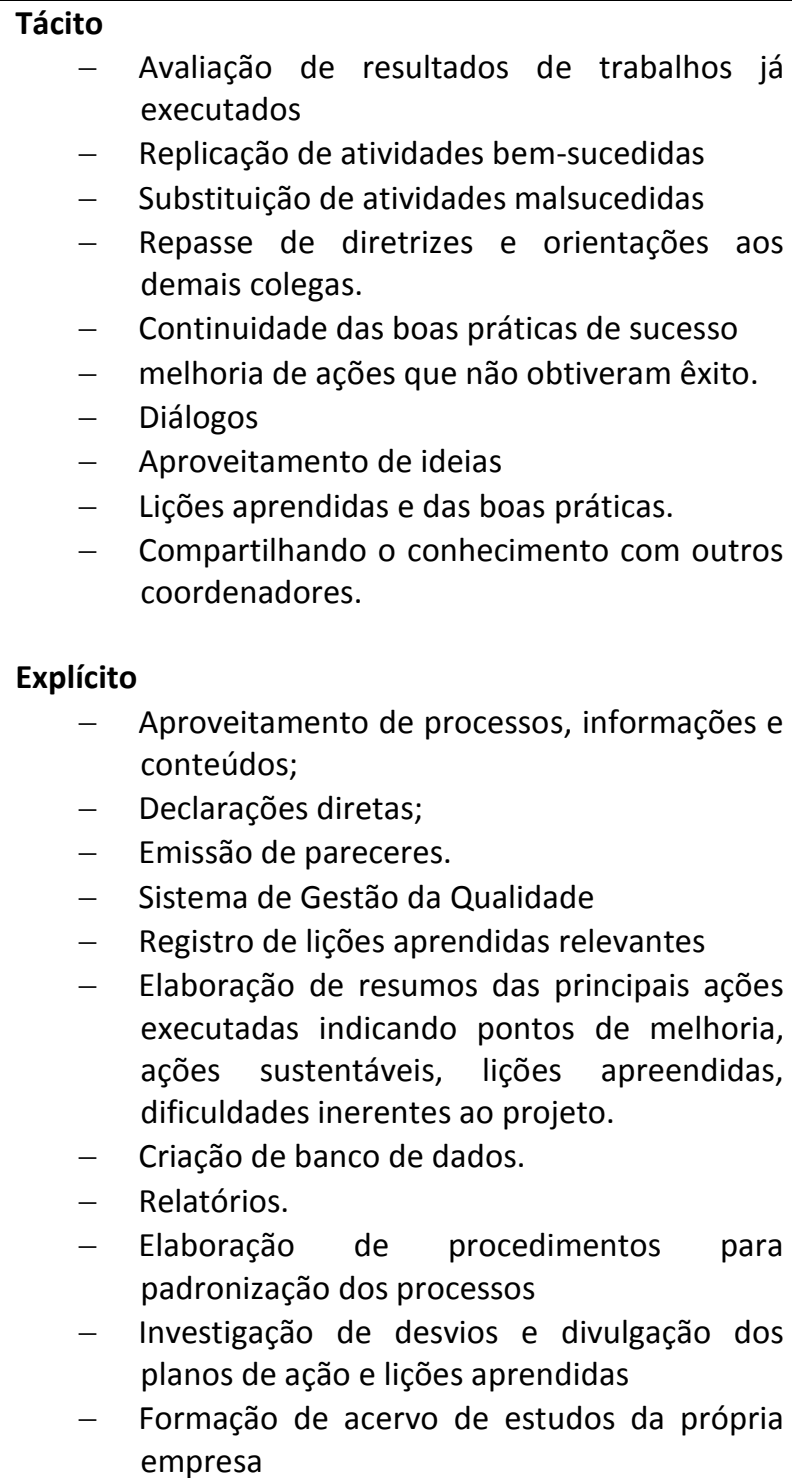 \\
\hline
\end{tabular}

Fonte: Dados da pesquisa (2018)

Conforme disposto no Quadro 6, quando questionados sobre como é feita a aquisição do conhecimento disponível nos órgãos ambientais, as respostas indicaram que com relação ao conhecimento tácito, são feitas reuniões e conversas com analistas do órgão ambiental, embora também existam relatos de consultas sobre informações do órgão ambiental à profissionais que já tenham trabalhado na região. Já a aquisição de conhecimento explícito é realizada pela consulta de documentos e estudos em sites, legislações, consultas formais, notícias e, mais formalmente, solicitando ao órgão ambiental vista a processos de licenciamento de outros empreendimentos. Alguns questionados também informaram que em virtude da dificuldade e burocratização na obtenção de informações, referentes à empreendimentos ou áreas de estudo similares, buscam informações em outras fontes.

Com relação à utilização do conhecimento tácito advindo de suas experiências, os profissionais questionados informaram que replicam atividades bem-sucedidas, repassam

Perspectivas em Gestão \& Conhecimento, João Pessoa, v. 9, n. 1, p. 266-284, jan./abr. 2019. 
informações e boas práticas para colegas. O processo de utilização do conhecimento explícito, por sua vez, se dá pelo aproveitamento de processos, informações e conteúdos de projetos anteriores, e pela consulta de relatórios e pareceres. Foram citados também a implantação de um sistema de gestão de qualidade e elaboração de procedimentos para elaboração de processos. Projetos antigos ainda permitem que a empresa crie seu próprio acervo e banco de dados, de acordo com os questionados.

Conforme relatado por um dos participantes da pesquisa, a implantação de um sistema eficiente e integrado de informações de meio ambiente promoveriam um avanço no resultado de programas ambientais, conforme segue:

As informações disponíveis em órgãos ambientais não estão sistematizadas (por atividade, georreferenciadas ou aptidão de cada região). O que temos disponível é, às vezes, acesso a um estudo ambiental. O Sistema Nacional do Meio Ambiente (SISNAMA) deveria criar e implementar nos diversos órgãos estaduais, os resultados dos diagnósticos ambientais e de execução dos programas ambientais, criando uma base nacional de consulta pública.

Em síntese, de acordo com os entrevistados, a aquisição do conhecimento pelas equipes de meio ambiente pode ser comprometida por problemas relacionados à disponibilização de informações por órgãos ambientais, deficiências no ensino durante a graduação e pela existência de estudos ambientais pouco qualificados que desconsideram a realidade local (estudos inicialmente elaborados para uma determinada região e aplicados em outra). Já a aquisição do conhecimento pode ser facilitada pela realização de reuniões, intercâmbio com profissionais de outras regiões, consulta à legislação e acesso à documentos e projetos já protocolados nos órgãos ambientais. A disponibilização destas informações, pelo órgão ambiental, de forma sistematizada, em plataforma digital, certamente contribui e facilita o acesso aos dados e conhecimentos gerados em projetos pretéritos.

Com relação à utilização e replicação dos conhecimentos, esbarra-se na falta de experiência dos profissionais e dificuldade para replicar lições aprendidas. Esta dificuldade de se replicar lições aprendidas é relatada com frequência por diversas empresas e projetos (DUFFIELD, WHITTY, 2015) e pode ser considerada como um diferencial competitivo para as organizações que souberem utilizar este conhecimento de forma mais eficiente.

Algumas especificidades de condicionantes ambientais e detalhamentos do Projeto Básico Ambiental podem prejudicar a utilização de conhecimentos já existentes, todavia para este caso cabem recursos como a revisão de condicionantes ou mesmo justificativas técnicas para alteração de metodologia em programas ambientais. As práticas relatadas, neste estudo de caso, para a utilização de conhecimento, envolvem desde diálogos entre a equipe e a replicação de atividades bem-sucedidas, até a criação de banco de dados, padronização de processos, acervo de relatórios além do registro e uso de Lições Aprendidas.

Apresentados os resultados da pesquisa, a próxima seção consolida o entendimento obtido a partir dos relatos dos coordenadores de programas ambientais e propõe sugestões para novas pesquisas.

\section{CONSIDERAÇÕES FINAIS}

Como forma de representar o esforço dispendido para atendimento do rito do licenciamento ambiental, estima-se que para cada um dos projetos serão apresentados ao órgão ambiental cerca de 60.000 páginas de relatórios referentes à evidências de execução de programas ambientais, excluindo-se deste quantitativo os estudos e projetos apresentados

Perspectivas em Gestão \& Conhecimento, João Pessoa, v. 9, n. 1, p. 266-284, jan./abr. 2019. 
anteriormente à concessão da licença de instalação. Todo este conhecimento, se não for sistematizado pelo órgão ambiental e empresas consultoras, pode ser desperdiçado.

Pode-se considerar, de forma simplificada, que o processo de licenciamento ambiental está dividido entre o conhecimento do empreendedor, de seus fornecedores e o conhecimento do órgão ambiental, onde este último representa, inclusive, os interesses da sociedade.

Num cenário ideal as esferas de atuação dos órgãos ambientais, quais sejam municipais, estaduais ou federal, deveriam formar um corpo único de conhecimento, recebendo estudos e informações de diversos locais e disponibilizando informações consolidadas para a sociedade e empreendedores. Assim o órgão ambiental dispõe de literatura, pesquisas acadêmicas em curso e novos estudos ambientais, os quais trazem informações atualizadas sobre determinada região.

$\mathrm{Na}$ pesquisa realizada com os coordenadores dos programas ambientais, onde todos os convidados participaram da pesquisa, nenhum deles relatou sobre processos formais de gestão do conhecimento. Afirmaram, porém, que encontram, mas com certa dificuldade, conhecimentos diversos junto ao órgão ambiental. Estes conhecimentos, se disponibilizados, por exemplo, na forma de banco de dados para a sociedade, proporcionariam um melhor aproveitamento do acervo da instituição. Da mesma forma, um esforço maior de consulta por parte dos consultores ambientais, mesmo que de maneira formal, solicitando vista a outros processos de licenciamento, também poderia contribuir para um melhor entendimento do programa ambiental que está se propondo a realizar.

Partindo do princípio que exista uma gestão de conhecimento efetiva no órgão ambiental, poder-se-ia solicitar, por parte do empreendedor, a implementação de planos e programas ambientais cada vez mais condizentes com a necessidade da região e, caso identificado uma deficiência na caracterização ambiental da área como a informações sobre determinada espécie animal, poderia ser solicitado de forma mais assertiva. Da mesma sorte, um processo formal de gestão do conhecimento no órgão ambiental poderia focar na disseminação e aquisição mais eficiente do conhecimento, favorecendo não só os consultores ambientais, mas os empreendedores e a sociedade como um todo.

No caso do empreendedor que replica os seus empreendimentos, pode-se afirmar que existe a necessidade de otimizar os projetos em todas as instâncias, seja pelas melores alternativas tecnológicas, seja pelo menor tempo de implantação. Assim, o licenciamento ambiental é caminho crítico do projeto deve receber atenção especial, pois quanto menor for o tempo do licenciamento, mais cedo o empreendimento estará apto a entrar em operação.

Com isso o empreendedor utiliza experiências pretéritas para promover melhorias nos seus novos projetos. Quando a gestão do conhecimento é utilizada de forma eficaz, as melhores práticas e a utilização de informações já existentes permitem a otimização do tempo e até mesmo de custos do projeto.

A prática de lições aprendidas relatada por muitos consultores como forma de reutilizar o conhecimento adquirido em projetos anteriores, muitas vezes é documentada de forma implícita e aplicada de forma equivocada, o que pode corroborar para o seu descrédito. São comuns os relatos de fracassos na aplicação de lições aprendidas por diversos motivos (DUFFIELD, WHITTY, 2015). Práticas como a de lições aprendidas, se implantadas com o apoio da gestão do conhecimento, podem trazer diversos benefícios para as organizações, como no caso dos empreendedores, consultores e órgãos ambientais.

A organização necessita ter, portanto, conhecimentos tácito e explícito, de forma a garantir o seu diferencial competitivo e eficácia em sua operação (NONAKA et al, 2003). Por este motivo, deve-se criar e gerir, conscientemente estes conhecimentos, proporcionando também um ambiente favorável à sua implementação e desenvolvimento. 
Isto posto, o objetivo deste trabalho foi alcançado através da aplicação de questionários aos coordenadores de programas ambientais participantes da construção de dois complexos eólicos distintos, profissionais estes que relataram suas principais dificuldades e facilidades para aplicação de gestão do conhecimento, além de suas práticas no uso e na aquisição do conhecimento. Ressalta-se também que o entendimento do processo do licenciamento ambiental no Brasil possibilita ao empreendedor otimizar seus esforços e atuar de forma mais assertiva no que tange ao atendimento das exigências legais e corporativas que dizem respeito ao meio ambiente.

Como possibilidades de se avançar cientificamente sobre o uso da gestão do conhecimento no licenciamento ambiental, sugere-se a aplicação de pesquisas semelhantes junto à órgãos ambientais e com empreendedores. Pelo fato de ser várias vezes citada no resultado desta pesquisa, considera-se pertinente também o aprofundamento nas pesquisas referentes à prática de lições aprendidas em processos de licenciamento ambiental.

\section{REFERÊNCIAS}

ASSOCIAÇÃO BRASILEIRA DE ENERGIA EÓLICA. Boletim Anual de Eólica 2017. Disponível em: http://www.abeeolica.org.br/wp-content/uploads/2018/04/Boletim-Anual-de-Geracao2017.pdf. Acesso em: 09 Maio 2018.

ANDERSON, Frederick R. NEPA in the courts: a legal analysis of the National Environmental Policy Act. RFF Press, 2013.

AGÊNCIA NACIONAL DE ENERGIA ELÉTRICA. Boletim de Informações Gerenciais. Junho de 2017. Disponível em http://www.aneel.gov.br/informacoes-gerenciais. Acesso em: 01 out. 2017.

BARBIERI, José Carlos. Avaliação de impacto ambiental na legislação brasileira. Revista de Administração de Empresas, v. 35, n. 2, p. 78-85, 1995.

CEDRICK, Bindzi Zogo Emmanuel; LONG, Pr Wei. Investment Motivation in Renewable Energy: A PPP Approach. Energy Procedia, v. 115, p. 229-238, 2017.

CONAMA, Resolução. 237/97. Política Nacional de Meio Ambiente, 1997.

DALKIR, Kimiz. Knowledge management in theory and practice. Oxford: Elsevier Butterworth Heinemann,2005.

DOS SANTOS PACHECO, Roberto Carlos; TOSTA, Kelly Cristina Benetti Tonani; DE SÁ FREIRE, Patricia. Interdisciplinaridade vista como um processo complexo de construção do conhecimento: uma análise do Programa de Pós-Graduação EGC/UFSC. Revista Brasileira de Pós-Graduação, v. 7, n. 12, 2010.

DUARTE, Rosália. Pesquisa qualitativa: reflexões sobre o trabalho de campo. Cadernos de pesquisa, n. 115, p. 139-154, 2002.

DUFFIELD, Stephen; WHITTY, S. Jonathan. Developing a systemic lessons learned knowledge model for organisational learning through projects. International journal of project management, v. 33, n. 2, p. 311-324, 2015. http://dx.doi.org/10.1016/j.ijproman.2014.07.004. 
FERENHOF, Helio Aisenberg et al. Uma sistemática de identificação de desperdícios de conhecimento visando à melhoria do processo de criação de novos serviços. 2011. Dissertação (Mestrado em Engenharia e Gestão do Conhecimento) - Universidade Federal de Santa Catarina, Florianópolis, 2011.

FERREIRA, W. Política de Conteúdo Local e Energia Eólica: a experiência Brasileira. 2017. Tese de Doutorado. PhD Thesis, Niterói: Universidade Federal Fluminense. Brasil.

GIL, Antonio Carlos. Como elaborar projetos de pesquisa, São Paulo, v. 5, n. 61, p. 16-17, 2002.

GONZALEZ, Rodrigo Valio Dominguez; MARTINS, Manoel Fernando. O Processo de Gestão do Conhecimento: uma pesquisa teórico-conceitual. Gestão \& Produção, p. 248-65, 2017.

HINNIG, M. P. F. Gestão do Conhecimento nas Práticas do PMBOK ${ }^{\circledR}$ : Uma Revisão Sistemática. In: SIMPÓSIO INTERNACIONAL DE GESTÃO DE PROJETOS, INOVAÇÃO E SUSTENTABILIDADE, 6., 2017, São Paulo. Anais [...]. São Paulo, 2017. Disponível em: https://singep.org.br/6singep/resultado/165.pdf.

MCCOMBIE, Charles; JEFFERSON, Michael. Renewable and nuclear electricity: Comparison of environmental impacts. Energy Policy, v. 96, p. 758-769, 2016.

MERRIAM, Sharan B.; TISDELL, Elizabeth J. Qualitative research: a guide to design and implementation. John Wiley \& Sons, 2015.

MMA (Ministério do Meio Ambiente). Licenciamento de parques eólicos. 2009: http://www.mma.gov.br/estruturas/164/ publicacao/164 publicacao 26022010101115.pdf. Acesso em 20 julho 2018.

NEVES, José Luis. Pesquisa qualitativa: características, usos e possibilidades. Caderno de pesquisas em administração, São Paulo, v. 1, n. 3, p. 1-5, 1996.

NONAKA, I.; TAKEUCHI, Hirotaka. Criação de conhecimento na empresa: como as empresas japonesas geram a dinâmica da inovação. Tradução de Ana Beatriz Rodrigues e Priscilla Martins Celeste. Rio de Janeiro: Campus, 1997.

NONAKA, Ikujiro; TAKEUCHI, Hirotaka. The knowledge-creating company: How Japanese companies create the dynamics of innovation. Long range planning, v. 4, n. 29, p. 592, 1995.

PANWAR, N. L.; KAUSHIK, S. C.; KOTHARI, Surendra. Role of renewable energy sources in environmental protection: a review. Renewable and Sustainable Energy Reviews, v. 15, n. 3, p. 1513-1524, 2011. https://doi.org/10.1016/j.rser.2010.11.037.

PROGRAMA DE PÓS-GRADUAÇÃO EM ENGENHARIA E GESTÃO DO CONHECIMENTO DA UNIVERSIDADE FEDERAL DE SANTA CATARINA. Disponível em: http://www.egc.ufsc.br/. Acesso em: 27 out. 2016. 
SIMAS, Moana Silva. Energia eólica e desenvolvimento sustentável no Brasil: estimativa da geração de empregos por meio de uma matriz insumo-produto ampliada. 2012. Tese (Doutorado) - Universidade de São Paulo, São Paulo, 2012.

STAUT, Fabiano. O processo de implantação de parques eólicos no nordeste brasileiro. 2011. 165f. Dissertação (Mestrado em Engenharia Ambiental Urbana) - Universidade Federal da Bahia, Salvador, 2011.

TRINDADE, Evelin Priscila et al. Sustainable development of smart cities: A systematic review of the literature. Journal of Open Innovation: Technology, Market, and Complexity, v. 3, n. 3, p. 11, 2017.

VENTURA, Magda Maria. O estudo de caso como modalidade de pesquisa. Revista SoCERJ, v. 20, n. 5, p. 383-386, 2007.

VIEGAS, Cláudia Viviane. Atividades de gestão do conhecimento na elaboração do estudo de impacto ambiental. 2009. 362f. Tese (Doutorado em Engenharia e Gestão do Conhecimento) Universidade Federal de Santa Catarina, Florianópolis, 2009.

WEINBERG, Alvin M. Are the alternative energy strategies achievable? Energy, v. 4, n. 5, p. 941-951, 1979.

WIIG, Karl M. Knowledge management: where did it come from and where will it go? Expert systems with applications, v. 13, n. 1, p. 1-14, 1997.

WORD WIND ENERGY ASSOCIATION. Wind Power Capacity Reaches 539 Gw, 52,6 Gw Added In 2017. Disponível em: http://www.wwindea.org/2017-statistics/

YIN, Robert K. Estudo de caso: planejamento e métodos. Bookman editora, 2001.

WEBER, Rosina O.; AHA, David W. Intelligent delivery of military lessons learned. Decision support systems, v. 34, n. 3, p. 287-304, 2003. 